\title{
Influence of subinhibitory levels of antibiotics on expression of Escherichia coli lipopolysaccharide and binding of anti-lipopolysaccharide monoclonal antibodies
}

\author{
D. NELSON, T. E. S. DELAHOOKE and I. R. POXTON*
}

Department of Medical Microbiology, University of Edinburgh Medical School, Teviot Place, Edinburgh EH8 9AG

\begin{abstract}
Summary. The expression of Escherichia coli lipopolysaccharide (LPS) and the binding capacity of anti-LPS monoclonal antibodies (MAbs) to E. coli grown in the presence or absence of subinhibitory concentrations of various antibiotics was studied. Four $E$. coli strains (three clinical blood-culture isolates and an isogenic, non-capsulate mutant of the O18:K1 parent) were grown in the presence of the $\beta$-lactam antibiotic, ampicillin, the aminoglycoside gentamicin, the fluoroquinolone ciprofloxacin and chloramphenicol. The techniques of silver staining, immunoblotting, whole-cell ELISA and flow cytometry were all used to monitor the expression of LPS on the bacteria and the binding of the anti-LPS MAbs. Treatment with ampicillin, chloramphenicol and ciprofloxacin resulted in enhanced binding of anti-core reactive MAbs to most $E$. coli strains. Overall, treatment with gentamicin produced the least effect on MAb binding. The presence of chloramphenicol decreased the expression of high molecular mass $\mathrm{O}$-antigen or increased the expression of low molecular mass substituted $E$. coli LPS or both. These results further illustrate that LPS core, especially the inner-core region, becomes more accessible to antibodies when bacteria are grown in the presence of certain antibiotics. Possible synergy between antibodies and antibiotics for treatment of septicaemia and septic shock remains an intriguing possibility.
\end{abstract}

\section{Introduction}

Gram-negative bacterial infections are serious, especially those associated with septicaemia and septic shock. It is well recognised that endotoxin, primarily the lipopolysaccharide (LPS) component of the gramnegative bacterial outer membrane, is one of the most important components in the development of these conditions. ${ }^{1}$ LPS acts as a potent activator of both humoral and cellular mediator systems and can induce the whole spectrum of acute pathophysiological manifestations associated with septicaemia and septic shock.

Intensive investigations have been undertaken to assess the potential of antibody therapy for the prevention and treatment of endotoxin-associated illnesses. ${ }^{2}$ Much attention has focused on the production and characterisation of monoclonal antibodies (MAbs) to common epitopes of endotoxin in the LPS core glycolipid. However, there is concern about the accessibility of these shared epitopes. ${ }^{3,4}$ Anti-LPS antibodies may be unable to recognise their targets and may fail to react with them.

It is now well established that the growth environment of bacteria greatly influences the phenotypic expression of surface characters. ${ }^{5}$ We have shown recently that both LPS expression and the binding of LPS MAbs depended on growth conditions. ${ }^{6}$ Several studies have also reported that subinhibitory concentrations of antibiotics could modulate smooth strains of gram-negative bacteria, enabling the binding of antibodies to conserved core and lipid $\mathrm{A}$ regions of LPS. ${ }^{7,8}$ In this study, the effects of subinhibitory levels of various antibiotics on the expression of Escherichia coli LPS and the binding of several anti-LPS MAbs to $E$. coli whole cells were investigated further.

\section{Materials and methods}

\section{Bacteria}

Two strains of $E$. coli were kindly supplied by Dr A. S. Cross, Walter Reed Institute for Army Research, Washington DC, USA: the clinical isolate, O18:K1 and a non-capsulate mutant $\left(\mathrm{O} 18: \mathrm{K}^{-}\right)$, an isogenic mutant from the $\mathrm{O} 18$ parent. Two further $E$. coli clinical isolates were kindly supplied by $\operatorname{Dr}$ A.P. Gibb, Department of Medical Microbiology, University of Edinburgh. These were of serotypes O18: K5 and $\mathrm{O} 1: \mathrm{K} 1$.

\section{Growth conditions}

Bacteria were studied after growth at $37^{\circ}$ to early 
Table I. MICs of ampicillin, chloramphenicol, gentamicin and ciprofloxacin for $E$. coli

\begin{tabular}{l|cccc}
\hline & \multicolumn{4}{|c}{ MIC (mg/L) of } \\
Strain & \multicolumn{4}{|c}{ ampicillin chloramphenicol gentamicin ciprofloxacin } \\
\cline { 2 - 5 } & & 8 & 0.5 & 0.008 \\
O18:K5 & 128 & 8 & 0.5 & 0.016 \\
O1:K1 & 2 & 8 & 0.5 & 0.016 \\
O18:K1 & 2 & 8 & 0.5 & 0.016 \\
O18:K & 2 & & & \\
\hline
\end{tabular}

Table II. MAbs in study

\begin{tabular}{|c|c|c|}
\hline MAb no. & Specifity & Isotype \\
\hline 184.2.5.5 & E. coli $\mathrm{O} 18, \mathrm{O}$-antigen & IgG \\
\hline 27.150 .3 & $\begin{array}{l}\text { Rc cross-reactive (anti-heptose), } \\
\text { reactive to both substituted and } \\
\text { unsubstituted core material }\end{array}$ & IgG2a \\
\hline 43.3.4.8 & $\begin{array}{l}\text { Outer-core } E \text {. coli } \mathrm{R} 1 \text { specific (anti- } \\
\text { hexose), reactive to core not substituted } \\
\text { with } \mathrm{O} \text {-antigen }\end{array}$ & IgG3 \\
\hline 43.27.11.2 & $\begin{array}{l}\text { Inner-core } \mathrm{Re} \text { cross-reactive (anti-lipid } \\
\mathrm{A}-\mathrm{KDO} \text { ), reactive to core not substituted } \\
\text { with } \mathrm{O} \text {-antigen }\end{array}$ & $\operatorname{IgG3}$ \\
\hline
\end{tabular}

stationary phase in nutrient broth (Gibco), in the presence and absence of 1 in 2,1 in 4 and 1 in $8 \mathrm{MIC}$ dilutions $(0.5,0.25$ and $0.125 \mathrm{MIC})$ of antibiotics.

\section{Antibiotics}

Ampicillin (SmithKline Beecham Research Laboratories, Brentford), chloramphenicol (Parke-Davies and Co., Hounslow, London), ciprofloxacin (Bayer UK, Hayward's Heath, West Sussex), and gentamicin (Parke-Davis and Co.) were used. Antibiotic solutions were prepared according to the manufacturers' instructions immediately before each experiment.

\section{MIC determination}

The MIC of each antibiotic was determined by the agar dilution method on IsoSensitest Agar (Oxoid) in two-fold dilutions. A multipoint inoculator (Mast Laboratories Ltd, Liverpool) delivered a standard inoculum of bacterial suspensions, containing $c$. $1 \times 10^{4}$ cells $\mathrm{ml}$. The MICs of each antibiotic for the $E$. coli strains are shown in table I.

\section{$M A b s$}

MAbs were prepared by fusing spleen cells from immune BALB/c mice with NS-O myeloma cells by standard techniques. The reactivity of the MAbs was determined by the LPS-polymyxin ELISA method. ${ }^{9}$ Full details of the immunisation of mice, selection of hybridomas and characterisation of MAbs are to be published elsewhere. Four MAbs with known specificities in the LPS-polymyxin ELISA were selected for this study as shown in table II. Supernates of hybrid- oma cell cultures grown in RPMI 1640 supplemented with fetal calf serum $5 \% \mathrm{v} / \mathrm{v}$ in $150-\mathrm{cm}^{2}$ flasks were used throughout. Cell cultures were grown to maximum cell density and harvested at $50 \%$ cell viability. These hybridomas gave yields of $c .50 \mu \mathrm{g} / \mathrm{ml}$.

\section{Preparation of LPS}

LPS was prepared from whole washed bacteria by the proteinase $\mathrm{K}$ method ${ }^{10}$ as described previously. ${ }^{11}$ The density of washed bacteria was adjusted to an $\mathrm{OD}_{525}$ of 0.5 before proteinase $\mathrm{K}$ treatment. This allowed direct comparison of cells from each culture.

\section{$P A G E$}

PAGE was performed on acrylamide $14 \% \mathrm{w} / \mathrm{v}$ slab gels with the Laemmli buffer system, ${ }^{12}$ except that SDS was omitted from the stacking and separating buffers. Samples (10 $\mu$ l for silver stain or $20 \mu \mathrm{l}$ for immunoblotting) of the proteinase K LPS extracts were loaded on to the gels. The LPS separating gels were stained with silver by the method of Tsai and Frasch, ${ }^{13}$ as modified by Hancock and Poxton. ${ }^{11}$

\section{Immunoblot transfer}

LPS separated by PAGE was electroblotted to nitrocellulose ${ }^{14}$ as described previously ${ }^{11}$ with BioRad buffers and substrate. Nitrocellulose membranes of $0.2 \mu \mathrm{m}$ pore size were obtained from Schleicher and Schuell and an anti-mouse IgG-horseradish peroxidase conjugate was used (ICN). Antibody culture supernates were diluted 1 in 10 .

\section{Dilutents and buffers used in ELISA}

Coating buffer consisted of $0.05 \mathrm{M}$ carbonatebicarbonate, pH 9.6. Post-coat buffer consisted of PBS (pH 7.2) containing bovine serum albumin (BSA) $2 \% \mathrm{w} / \mathrm{v}(\mathrm{ICN})$. Wash buffer consisted of PBS containing Tween $20 \quad 0.05 \% \quad \mathrm{v} / \mathrm{v}$. Dilution buffer consisted of PBS containing Tween 20 $0.05 \% \mathrm{v} / \mathrm{v}, \mathrm{BSA} 0.05 \%$ and polyethylene glycol 6000 (Sigma) $4 \% \mathrm{w} / \mathrm{v}$. All solutions contained sodium azide $0.02 \%$.

\section{ELISA procedure}

After measuring the $\mathrm{OD}_{540}$ of washed bacteria and then diluting with coating buffer to produce a concentration of $2 \times 10^{7} \mathrm{cell} / \mathrm{ml}$, ELISA strips (Immuno module Polysorp F8, Nunc) were coated with $100 \mu \mathrm{l} /$ well. Coating was promoted by centrifugation at $630 \mathrm{~g}$ for $4 \mathrm{~min}$ and incubation overnight at room temperature. Plates were washed four times in wash buffer before post-coating with post-coat buffer at $100 \mu \mathrm{l} /$ well overnight at room temperature. After further washing, plates were rinsed in distilled water and stored at $-20^{\circ} \mathrm{C}$ until required. MAb supernates were 
diluted 1 in 10, 40, 160 and 640 in dilution buffer and added to coated microtitration plates at $100 \mu \mathrm{l} /$ well in triplicate. Plates were incubated at $37^{\circ} \mathrm{C}$ for $90 \mathrm{~min}$ before washing four times with wash buffer. Ureaseconjugated sheep anti-mouse Ig (SeraLab) was diluted 1 in 500, added at $100 \mu \mathrm{l} /$ well and the plates were incubated for a further $90 \mathrm{~min}$ at $37^{\circ} \mathrm{C}$. Plates were washed four times and rinsed in distilled water before $100 \mu$ l of urease substrate (SeraLab) was added to each. Plates were incubated for $60 \mathrm{~min}$ at room temperature, then the OD was measured at $590 \mathrm{~nm}$ with an Anthos reader 2001 (Denley Instruments Ltd, Billingshurst, Sussex). The $\mathrm{OD}_{590}$ readings were calculated by subtraction of the $\mathrm{OD}_{590}$ of negative control wells (coated with BSA post-coat only) for each MAb.

ELISA titres were defined as the dilution of MAb showing an $\mathrm{OD}_{590}$ of $0 \cdot 2$. If an $\mathrm{OD}_{590}$ of $0 \cdot 2$ was not reached, the reaction was considered to be negative. Since differences in coating efficiency may occur between the different antigens, ELISA titre ratios were compared instead of absolute titres. ${ }^{7}$ The ratio was defined as the titre obtained with a certain MAb to a strain grown in the presence of antibiotic, divided by the titre obtained with the same MAb to this strain in the absence of antibiotic. In terms of MAb binding, only ratios $>2$ were considered to be significant.

\section{Flow cytometry}

Flow cytometry was based on the method described previously. ${ }^{15}$ Briefly, washed cultures of bacteria were resuspended to a concentration of $c .1 \times 10^{8}$ cells $/ \mathrm{ml}$. Pellets from $1 \mathrm{ml}$ were resuspended in $1 \mathrm{ml}$ of MAb culture supernate, diluted 1 in 10 in dilution buffer (see ELISA methodology), and incubated for $60 \mathrm{~min}$ at $37^{\circ} \mathrm{C}$. After washing twice in PBS, $0.5 \mathrm{ml}$ of sheep FITC-conjugated anti-mouse IgG (ICN), diluted 1 in 100 in dilution buffer, was added and incubated for $60 \mathrm{~min}$ at $37^{\circ} \mathrm{C}$. After further washing in PBS, the pellet was resuspended in PBS containing formaldehyde $0.5 \%$. Samples were diluted 1 in 50 in PBS and analysed in an EPICS "C" (Coulter Electronics) flow cytometer with a $5 \mathrm{~W}$ argon ion laser operating at $500 \mathrm{~mW}$ and exciting at $488 \mathrm{~nm}$. A total of 50000 cells at 500 cells/s were passed through the beam from a 76- $\mu \mathrm{m}$ tip. Background noise and clumps of cells were excluded by a gate on the log forward angle light scatter. The percentage of cells exhibiting positive staining was calculated with the EPICS "Stat Pack" program.

\section{Results}

\section{Silver staining and immunoblot analysis of LPS}

The silver-stained LPS profiles of E. coli O18:K1 grown in the presence and absence of sub-MICs of ampicillin, chloramphenicol and gentamicin are shown in figure 1a. Major changes in LPS expression were observed only for bacteria cultured in the presence of chloramphenicol (tracks 5-7). These changes included an increased expression of low molecular mass $\mathrm{O}$ antigen-substituted LPS bands, especially that substituted with 2, 3 and 4 repeating units (bands 3, 4 and 5 from the bottom of the gel) and a decreased expression of high molecular mass, $\mathrm{O}$-antigen-bearing LPS bands (tracks 5-7). These changes were more prominent for the two lowest sub-MIC dilutions ( 1 in 2 and 1 in 4 ; tracks 5 and 6). Similar findings were observed with other $E$. coli strains.

Immunoblotting LPS profiles of $E$. coli O18:K1 with O18, O-antigen-specific MAb 184.2.5.5 (fig. 1b) and core-specific 27.150 .3 (fig. 1c) further demonstrated very clearly the increased expression of low molecular mass material from cells exposed to chloramphenicol (tracks 5-7) compared to untreated cells.

Silver staining and immunoblot analysis of $E$. coli strains grown in the presence of sub-MICs of ciprofloxacin showed no major differences in LPS profiles from those of untreated cells. However, there was a slight increase in the length of the $\mathrm{O}$-side chains; five or six additional high molecular mass bands were observed after treatment with 0.5 -MIC of ciprofloxacin.

\section{ELISA}

ELISA titre ratios of anti-LPS MAbs against four E. coli strains grown in the presence of antibiotics are presented in table III. Overall, treatment of cells with various antibiotics did not alter the binding of $\mathrm{O}$ antigen-specific MAb 184.2.5.5. Any significant differences that did occur were seen in cells treated with ciprofloxacin, illustrated by $E$. coli $\mathrm{O} 18: \mathrm{K}^{-}$.

The three anti-core MAbs (27.150.3, 43.3.4.8 and 43.27.11.2) all showed increased reactivity against some or all smooth $E$. coli grown in the presence of antibiotics compared to untreated cells. Those antibiotics inducing the greatest increases were ampicillin, chloramphenicol and ciprofloxacin. Gentamicin exerted the least effect of MAb binding.

\section{Flow cytometry}

To investigate further changes in binding activities of anti-LPS MAbs to whole cells exposed to sub-MICs of antibiotics, flow cytometry analysis was performed. Fig. 2 shows representative flow cytometry profiles of MAbs to whole cells of $E$. coli $\mathrm{O} 18: \mathrm{K} 1$ grown in the presence or absence of $0.5 \mathrm{MIC}$ of various antibiotics. The fluorescence patterns produced by 018 , Oantigen-specific MAb 184.2.5.5 against treated and untreated O18:K1 cells varied considerably. Significant changes in positive fluorescence levels were observed for cells exposed to chloramphenicol (45\%) and ciprofloxacin (87\%) compared to untreated cells $(70 \%)$.

The core-specific MAb 27.150.3 showed weak binding levels $(<5 \%)$ to smooth $E$. coli O18:K1 not exposed to antibiotics. However, growth in the pres- 

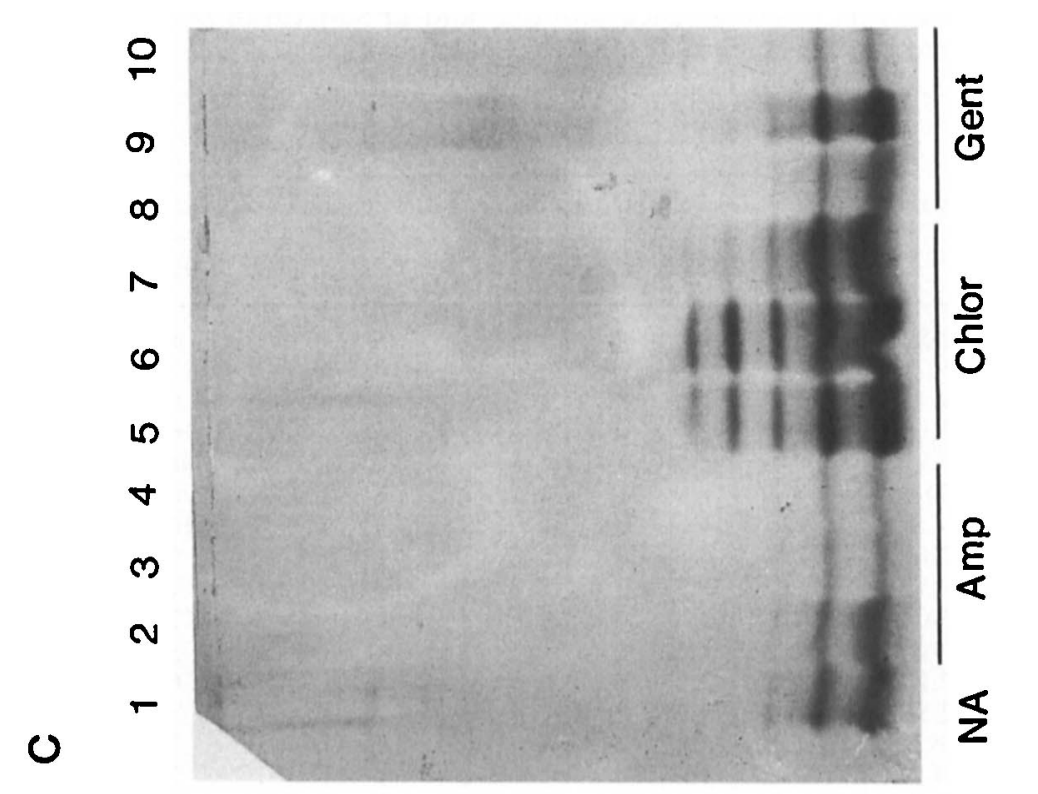

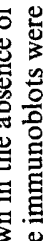

品焉.

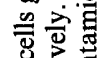

e 苞范

这造

놀

$反 \quad$ 焉总

记

율 웅 영

형

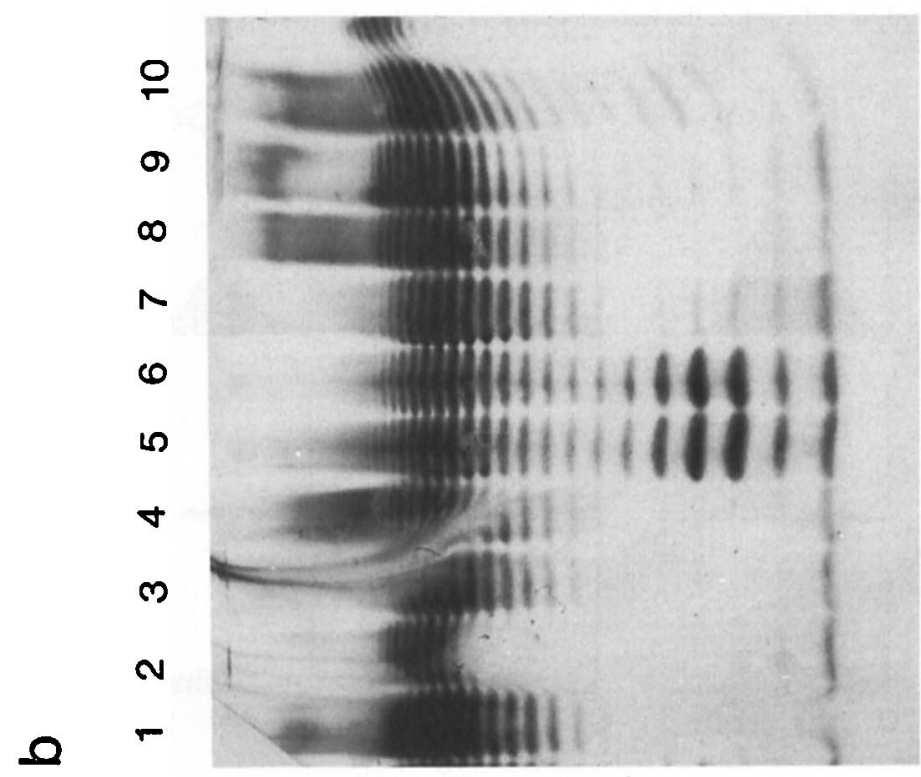

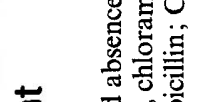

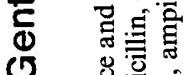

(1) 递家 若客

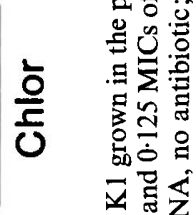

获已

을 융

< 近苍

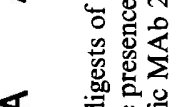

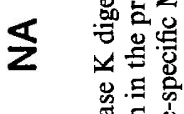
灵 步 음 50

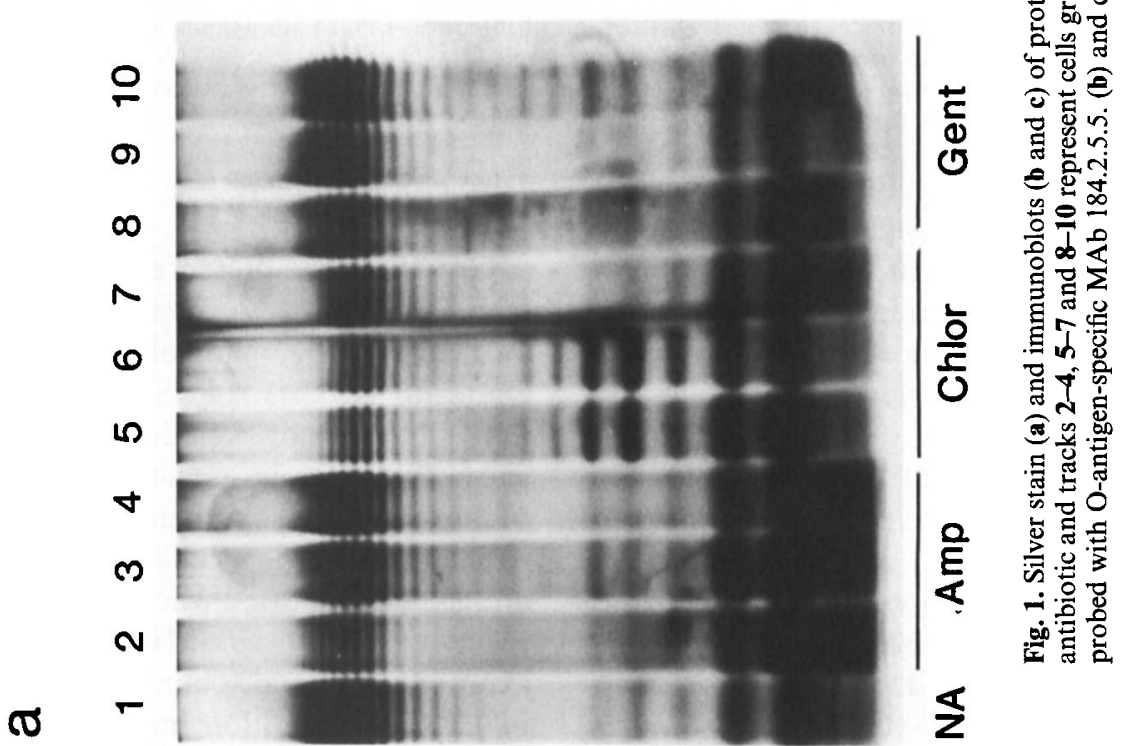


Table III. ELISA titre ratios obtained with four anti-LPS MAbs to E. coli strains grown in the presence or absence of sub-MICs of antibiotics

\begin{tabular}{|c|c|c|c|c|c|c|c|c|c|c|c|c|c|}
\hline \multirow{4}{*}{$\begin{array}{l}\begin{array}{l}\text { E. coli } \\
\text { strain }\end{array} \\
\text { O18:K5 }\end{array}$} & \multirow{4}{*}{$\begin{array}{l}\text { MAb no. } \\
184.2 .5 .5\end{array}$} & \multicolumn{12}{|c|}{ ELISA titre ratio with MIC dilutions of } \\
\hline & & \multirow{2}{*}{\multicolumn{3}{|c|}{$\frac{\text { ampicillin }}{0.5 \quad 0.250 .125}$}} & \multicolumn{3}{|c|}{ chloramphenicol } & \multirow{2}{*}{\multicolumn{3}{|c|}{$\frac{\text { gentamicin }}{0.50 .250 .125}$}} & \multirow{2}{*}{\multicolumn{3}{|c|}{$\frac{\text { ciprofloxacin }}{0.50 .250 .125}$}} \\
\hline & & & & & 0.5 & $0 \cdot 25$ & $0 \cdot 125$ & & & & & & \\
\hline & & 1 & 1 & 1 & 1 & 1 & 1 & 1 & 1 & 1 & 1 & 1 & \\
\hline \multirow{7}{*}{$\mathrm{O} 1: \mathbf{K} \mathbf{1}$} & 27.150 .3 & 14 & 14 & 10 & 20 & 20 & 16 & 10 & 6 & 1 & 12 & 9 & 9 \\
\hline & 43.3 .4 & 2 & 2 & 1 & 6 & 3 & 3 & 4 & 6 & 1 & 4 & 1 & 1 \\
\hline & 43.27 .11 .2 & 18 & 18 & 12 & 4 & 2 & 1 & 5 & 5 & 1 & 16 & 16 & 4 \\
\hline & 184.2 .5 .5 & NC & $\mathrm{NC}$ & $\mathrm{NC}$ & $\mathrm{NC}$ & NC & $\mathrm{NC}$ & NC & NC & $\mathrm{NC}$ & NC & $\mathrm{NC}$ & $\mathrm{NC}$ \\
\hline & 27.150 .3 & 1 & 4 & 1 & 86 & 93 & 8 & 6 & 1 & 1 & 20 & 16 & 17 \\
\hline & 43.3 .4 .8 & 16 & 16 & 4 & 35 & 30 & 29 & 5 & 4 & 4 & 16 & 16 & 14 \\
\hline & 43.27 .1 & 7 & 7 & 4 & 2 & 2 & 1 & 1 & 1 & 1 & 9 & 9 & 4 \\
\hline \multirow[t]{4}{*}{$\mathrm{O} 18: \mathrm{K} 1$} & 184.2 .5 .5 & 1 & 1 & 1 & 1 & 1 & 1 & 1 & 1 & 1 & 1 & 1 & 1 \\
\hline & 27.150 .3 & 16 & 16 & 4 & 8 & 8 & 8 & 1 & 1 & 1 & 13 & 8 & 10 \\
\hline & 43.3.4.8 & 4 & 1 & 1 & 1 & 1 & 1 & 4 & 1 & 1 & 3 & 3 & 1 \\
\hline & 43.27 .11 .2 & 3 & 2 & 2 & 6 & 8 & 4 & 3 & 1 & 1 & 6 & 7 & 6 \\
\hline \multirow[t]{4}{*}{$\mathrm{O} 18: \mathrm{K}^{-}$} & 184.2 .5 .5 & 1 & 1 & 1 & 1 & 1 & 1 & 1 & 1 & 1 & 3 & 1 & 1 \\
\hline & 27.150 .3 & 16 & 16 & 4 & 6 & 6 & 2 & 1 & 1 & 1 & 7 & 8 & \\
\hline & 43.3 .4 .8 & 1 & 1 & 1 & 1 & 1 & 1 & 1 & 1 & 1 & 1 & 1 & 1 \\
\hline & 43.27 .11 .2 & 4 & 3 & 3 & 13 & 16 & 16 & 1 & 1 & 1 & 4 & 4 & 1 \\
\hline
\end{tabular}

$\mathrm{NC}$, not calculated $(\mathrm{OD}<0 \cdot 2)$. Results were calculated from the means of triplicate readings; $1=\leqslant 1$.

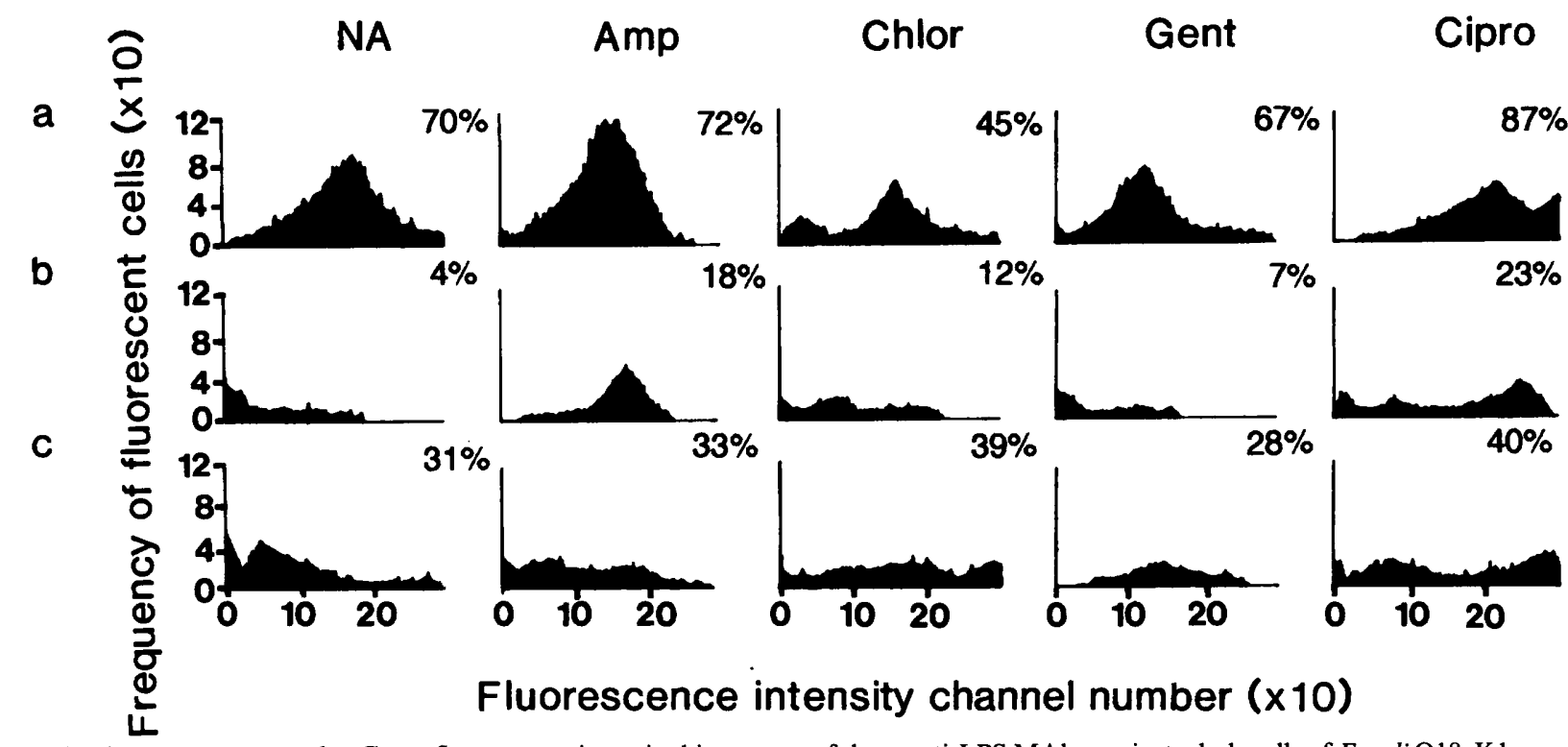

Fig. 2. Flow cytometry results. Green fluorescence intensity histograms of three anti-LPS MAbs against whole cells of $E$. coli $\mathrm{O} 18$ : K1 grown in the presence or absence of $0.5 \mathrm{MIC}$ of various antibiotics. MAbs used were O18, O-antigen-specific MAb 184.2.5.5 (a) and two core-specific MAbs, 27.150.3 (b) and 43.3.4.8 (c). Percentage values represent bacteria exhibiting positive fluorescence above background levels. NA, no antibiotic; Amp, ampicillin; Chlor, chloramphenicol; Gent, gentamicin; Cipro, ciprofloxacin.

ence of sub-MIC levels of ampicillin, chloramphenicol and ciprofloxacin all resulted in significant increases in positive fluorescence levels when probed with $\mathrm{MAb}$ 27.150.3. Those samples with an increased percentage of cells with positive fluorescence also demonstrated greater fluorescence intensity levels as shown by differences in the flow cytometry profiles of antibiotictreated and untreated cells. Small increases in positive fluorescence values were observed for cells exposed to the different antibiotics and probed with MAb 43.3.4.8, reactive against the outer-core LPS region. Gentamicin induced only minor increases in the binding of MAbs 27.150.3 and 43.3.4.8 to the smooth E. coli O18:K1, against untreated control cells. Similar findings were observed for other $E$. coli strains.

\section{Discussion}

Growth in the presence of sub-MICs of antibiotics has been shown to affect the synthesis of various virulence factors, many of which may help the host to eradicate bacteria. ${ }^{16,17}$ Several reports have shown that inhibition of peptidoglycan synthesis can influence LPS synthesis, including a reduction in the length of the O-antigen side chain of $E$. coli following growth in the presence of mecillinam. ${ }^{18} \mathrm{~A}$ similar loss of $\mathrm{O}$ antigen was reported when $E$. coli $\mathrm{O} 111$ was grown in the presence of sub-MICs of carumonam which, exposed the core glycolipid. ${ }^{8}$ In contrast, stimulation of LPS incorporation into the outer membrane has been demonstrated with certain $\beta$-lactam antibiotics. ${ }^{19}$ 
In this study, the major change in LPS expression shown after growth with sub-MICs of antibiotics was a relatively small reduction in $\mathrm{O}$-antigen material or greater expression of lower molecular mass LPS bands or both. It is possible that sub-MICs of chloramphenicol may affect the production of enzymes involved in the polymerization of the O-side chain.

The techniques of whole-cell ELISA and flow cytometry showed that sub-MICs of various antibiotics enhanced significantly the binding of corereactive murine MAbs to a number of smooth $E$. coli strains. Whilst flow cytometry lacks the sensitivity and automation of ELISA, the technique offered the advantages of investigating the surface properties of antibiotic-treated cells under physiological conditions, without some of the potentially distorting influences present in other methods. ${ }^{15,20}$

An alteration in LPS composition in chloramphenicol-treated $E$. coli strains may have contributed to the increased exposure of core epitopes. However, failure to demonstrate by PAGE any significant differences in LPS or protein composition in the bacterial cell wall, after growth with most antibiotics, indicates that major qualitative differences in cell-wall composition are not responsible for the increased anticore LPS MAb binding. The ability of sub-MICs of various, unrelated antibiotics to increase the exposure of relatively inaccessible epitopes is, perhaps, mainly attributable to their modes of action. $\beta$-Lactam antibiotics, such as ampicillin, directly affect the synthesis of the bacterial cell wall by interfering with the crosslinking of the peptidoglycan backbone. ${ }^{21}$ Ciprofloxacin affects DNA synthesis in bacteria ${ }^{22}$ which may cause several different metabolic and structural disorders. Enhanced binding of core-reactive MAbs to bacteria grown in the presence of either antibiotic could, therefore, be explained by a disturbed cell-wall composition which unmasks relatively inaccessible $\mathbf{R}$ LPS determinants. Cell elongation induced by both ampicillin and ciprofloxacin may also impair the integrity of the cell wall, thus permitting greater accessibility of antibody to cell-surface antigens such as LPS. Sub-MICs of inhibitors of protein synthesis, including chloramphenicol and gentamicin, may impair synthesis of enzymes involved in cell-wall synthesis and expose inner core structures, and result in enhanced binding of MAbs. It has been proposed that polycationic antibiotics such as gentamicin may disrupt the LPS- $\mathrm{Mg}^{2+}$ cross bridges, rearrange the LPS "packaging", and result in the formation of "cracks" in the membrane structure. ${ }^{23}$ However, observations made in this study indicate that of those antibiotics used, gentamicin had the least effect on anti-LPS MAb binding.

Certain antibiotics, present at subinhibitory levels, are known to influence the production of capsules. ${ }^{24,25}$ Similar increases in binding of anti-core MAbs to antibiotic-treated cells of the relatively thin capsulate E. coli $\mathrm{O} 18: \mathrm{K} 1$, and to its non-capsulate isogenic mutant, indicate that any reduction in capsule ex- pression plays only a minor role in increasing the exposure of core epitopes. In contrast, the retention of some capsule has been shown to limit the increased accessibility of more deeply situated antigenic epitopes compared to non-capsulate strains. ${ }^{7}$ This effect depended on the relative thickness of the capsule. Variability in response among different $E$. coli strains to the effect of antibiotics on the binding of anti-LPS MAbs observed in this study is, perhaps, the result of a combination of factors. These may include the type and thickness of capsule, O-serotype, and the ability of the antibiotic to permeate the outer membrane. Similarly, the relative increase in MAb binding between those directed towards either inner or outer core LPS epitopes also varied amongst $E$. coli strains. This again perhaps reflects differences in the ability of strains to mask specific epitopes after antibiotic treatment.

Results presented in this study lend additional support to the growing body of evidence for the potential clinical application of sub-MICs of antibiotics. Possible synergy between antibodies and antibiotics presents intriguing possibilities for both the prevention and treatment of septicaemia and septic shock in immunocompetent as well as immunocompromised hosts. ${ }^{26}$ The potential of antibiotics to improve the exposure of conserved LPS epitopes targeted by immunotherapeutic MAbs is likely to improve the clinical efficacy of such MAbs. The exposure of deeper antigenic determinants by subMICs of certain antibiotics has the additional advantage of influencing host defences, which include the promotion of opsonisation by serum complement or antibodies, thus enhancing phagocytosis.

Evidence of greater accessibility of LPS epitopes after antibiotic treatment was highlighted in an investigation with HA-1A, a human IgM MAb for use in septic shock. ${ }^{27}$ These authors demonstrated a dramatic increase in the expression of its epitope on the lipid A domain of endotoxin after treatment of bacteria with cell-wall active antibiotics. However, the relevance of such studies, particularly the effect of sub-MICs of antibiotics in vivo, needs to be established. Most investigations have been in vitro, quite different from the environment in vivo, where nutrient limitation and presentation of the LPS molecule will influence profoundly its susceptibility to both host defences and to therapeutic agents.

We thank Dr G. R. Barclay and colleagues at the SE Scotland Blood Transfusion Service for their interest and collaboration in the project, and in the selection of MAbs. Also, we thank W. Neill of the Department of Medical Microbiology for his technical expertise in flow cytometry. This work was funded by Sandoz.

\section{References}

1. Ryan JL. Microbial factors in pathogenesis: lipopolysaccharides. In: Root RK, Sande MA (eds) Septic shock. New York, Churchill Livingstone. 1985: 13-25.

2. Barclay GR. Antibodies to endotoxin in health and disease. Rev Med Microbiol 1990; 1: 133-142.

3. Gigliotti F, Shenep JL. Failure of monoclonal antibodies to core glycolipid to bind intact smooth strains of Escherichia coli. J Infect Dis 1985; 151: 1005-1011. 
4. Pollack M, Raubitschek AA, Larrick JW. Human monclonal antibodies that recognise conserved epitopes in the corelipid A region of lipopolysaccharides. J Clin Invest 1987; 79: $1421-1430$

5. Brown MRW, Williams $P$. The influence of environment on envelope properties affecting survival of bacteria in infections. Annu Rev Microbiol 1985; 39: 527-556.

6. Nelson D, Bathgate AJ, Poxton IR. Monoclonal antibodies as probes for detecting lipopolysaccharide expression on Escherichia coli from different growth conditions. J Gen Microbiol 1991; 137: 2741-2751.

7. Overbeek BP, De Vos NM, Keller N, Raponi G, RozenbergArska M, Verhoef J. Enhanced binding of murine monoclonal antibodies to lipopolysaccharide structures of Enterobacteriaceae after treatment with antibiotics. Serodiagn Immunother Infect Dis 1989; 4: 39-51.

8. Overbeek BP, Schellekens JFP, Lippe W, Dekker BAT, Verhoef J. Carumonam enhances reactivity of Escherichia coli with mono- and polyclonal antisera to rough mutant Escherichia coli J5. J Clin Microbiol 1987; 25: 1009-1013.

9. Scott BB, Barclay GR. Endotoxin-polymyxin complexes in an improved enzyme-linked immunosorbent assay for IgG antibodies in blood donor sera to Gram-negative endotoxin core glycolipids. Vox Sang 1987; 52: 272-280.

10. Hitchcock PJ, Brown TM. Morphological heterogeneity among Salmonella lipopolysaccharide chemotypes in silver-stained polyacrylamide gells. $J$ Bacteriol $1983 ; 154$ : 269-277.

11. Hancock IC, Poxton IR. Bacterial cell surface techniques. Chichester, John Wiley and Sons. 1988: 92-93, 202-207, 281.

12. Laemmli UK. Cleavage of structural proteins during the assembly of the head of bacteriophage T4. Nature 1970; 227: $680-685$.

13. Tsai C-M, Frasch CE. A sensitive silver stain for detecting lipopolysaccharide in polyacrylamide gels. Anal Biochem 1982; 119: 115-119.

14. Towbin H, Staehelin T, Gordon J. Electrophoretic transfer of proteins from polyacrylamide gels to nitrocellulose sheets procedure and some applications. Proc Natl Acad Sci USA $1979 ; 76: 4350-4354$.

15. Nelson D, Neill W, Poxton IR. A comparison of immunoblotting, flow cytometry and ELISA to monitor the binding of anti-lipopolysaccharide monoclonal antibodies. $J$ Immunol Methods 1990; 133: 227-233.
16. Gemmell CG. Changes in expression of bacterial surface antigens induced by antibiotics and their influence on host defences. Pathol Biol 1987; 35: 1377-1381.

17. Shibl AM. Effect of antibiotics on production of enzymes and toxins by microorganisms. Rev Infect Dis $1983 ; 5: 865-875$.

18. Taylor PW, Gaunt H, Unger FM. Effect of sub-inhibitory concentrations of mecillinam on the serum susceptibility of Escherichia coli strains. Antimicrob Agents Chemother 1981; 19: 786-788.

19. Essig P, Martin HH, Gmeiner J. Murein and lipopolysaccharide biosynthesis in synchronized cells of Escherichia coli $\mathrm{K} 12$ and the effect of penicillin $\mathrm{G}$, mecillinam, and nalidixic acid. Arch Microbiol 1982; 132: 245-250.

20. Nelson D. Flow cytometry in bacteriology. Rev Med Microbiol (in press).

21. Atkinson BA, Amaral L. Sublethal concentrations of antibiotics, effects on bacteria and the immune system. CRC Crit Rev Microbiol 1982; 9: 101-138.

22. Wolfson JS, Hooper DC. The fluoroquinolones: structures, mechanisms of action and resistance, and spectra of activity in vitro. Antimicrob Agents Chemother 1985; 28: 581-586.

23. Peterson AA, Hancock REW, McGroarty EJ. Binding of polycationic antibiotics and polyamines to lipopolysaccharides of Pseudomonas aeruginosa. J Bacteriol 1985; 164: 1256-1261.

24. Raponi G, Keller N, Overbeek BP, Rozenberg-Arska M, Van Kessel KPM, Verhoef J. Enhanced phagocytosis of encapsulated Escherichia coli strains after exposure to sub-MICs of antibiotics is correlated to changes of the bacterial cell surface. Antimicrob Agents Chemother 1990; 34: 332-336.

25. Veringa E, Box A, Rozenberg-Arska M, Verhoef J. Monobactam antibiotics in sub-inhibitory concentrations enhance opsonophagocytosis and serum bacteriolysis in certain Escherichia coli strains. Drugs Exp Clin Res 1988; XIV : $1-8$.

26. Overbeek BP, Vergina EM. Role of antibodies and antibiotics in aerobic Gram-negative septicaemia: possible synergism between antimicrobial treatment and immunotherapy. Rev Infect Dis 1991; 13: 751-760.

27. Bogard WC, Siegel SA. The human monoclonal antibody HA1A: studies on the epitope location within the endotoxin molecule and epitopic exposure on the surface of viable Gram-negative bacteria. Abstract no. 332. Circ Shock $1991 ; 34: 119$ 